\title{
Analysis of left ventricular wall movement before and after reimplantation of anomalous left coronary artery in infancy
}

Julene S Carvalho, Andrew N Redington, Paul J Oldershaw, Elliot A Shinebourne, Christopher R Lincoln, Derek G Gibson

\begin{abstract}
Five infants who underwent direct reimplantation or redirection of an anomalous left coronary artery from the pulmonary artery to the aorta were studied. There were no deaths from the procedure. Anastomoses were patent at a mean follow up of 33 months. Left ventricular angiograms before and after operation were digitised frame by frame. Analysis of wall motion showed considerable generalised hypokinesia with no change in cavity shape before operation. After reimplantation there was a significant improvement of global ventricular function as assessed by ejection fraction and end diastolic shape index. There was also a tendency for the shape index change to increase; this was compatible with better global systolic function. Three of the four patients who were restudied showed normal isometric and contour wall motion plots. One child, the oldest at the time of operation, still showed asynchronous onset of contraction and isovolumic relaxation.
\end{abstract}

The procedure offers a low risk of mortality and a high rate of patency of the anastomosis. Improvement of ventricular function can be remarkable and its extent cannot be assessed simply by ejection fraction measurements.

Department of Paediatric Cardiology, Royal Brompton National Heart and Lung Hospital, London J S Carvalho

A N Redington

E A Shinebourne

Department of Cardiology, Royal

Brompton National

Heart and Lung

Hospital, London

PJ Oldershaw

D G Gibson

Department of Surgery, Royal

Brompton National

Heart and Lung

Hospital, London

C R Lincoln

Correspondence to Dr Julene $\mathbf{S}$ Carvalho, Department of Paediatric Cardiology, Royal Brompto National Heart and Lung Hospital, Sydney Street, London SW 36 NP.

Accepted for publication 6 December 1990
Anomalous origin of the left coronary artery from the pulmonary artery is a rare congenital anomaly. Infants presenting with heart failure from impaired left ventricular function have a high mortality and morbidity without operation. ${ }^{1}$ It is now clear that establishment of a two coronary artery system is the treatment of technique in which the left coronary artery is tunnelled into the aorta via a pulmonary artery baffle and aortopulmonary window. ${ }^{34}$ ventricular function has been documented after operation (for example, an increased ejection fraction), we know of only a few studies $^{5}$ of wall movement. An earlier operation may reduce the number of persistent wall motions abnormalities and hence the risk of late sudden arrhythmic deaths if such abnormalities reflect electrical instability ${ }^{6}$ at junctions of normal and impaired myocardium. choice either by direct reimplantation ${ }^{2}$ or by a

While improvement of global indices of left
Patients and methods

From October 1984 to March 1989, five infants with an anomalous left coronary artery arising from the pulmonary artery underwent operation at the Brompton Hospital. They all presented with heart failure and evidence of myocardial infarction or ischaemia on the electrocardiogram. The diagnosis was suspected on echocardiography and confirmed at cardiac catheterisation when selective right coronary artery injection showed late filling of the left coronary system. Preoperative left ventricular angiograms were available in four.

The mean age at operation was 4.2 months (range 2.8-5.7) and mean weight $4.6 \mathrm{~kg}$ (range $3 \cdot 6-5 \cdot 6)$. Cardiopulmonary bypass was used in two and deep hypothermia with circulatory arrest in the other three. Direct reimplantation was possible in four while an intrapulmonary pericardial baffle was constructed in the remaining infant. ${ }^{4}$

Cardiac catheterisation and angiography were performed postoperatively in four patients at a mean of 33 months (range 22-40) after the operation. The left coronary artery was selectively injected through a 5F Amplatz or left Judkins catheter. Left ventricular angiograms obtained in the $30^{\circ}$ right anterior
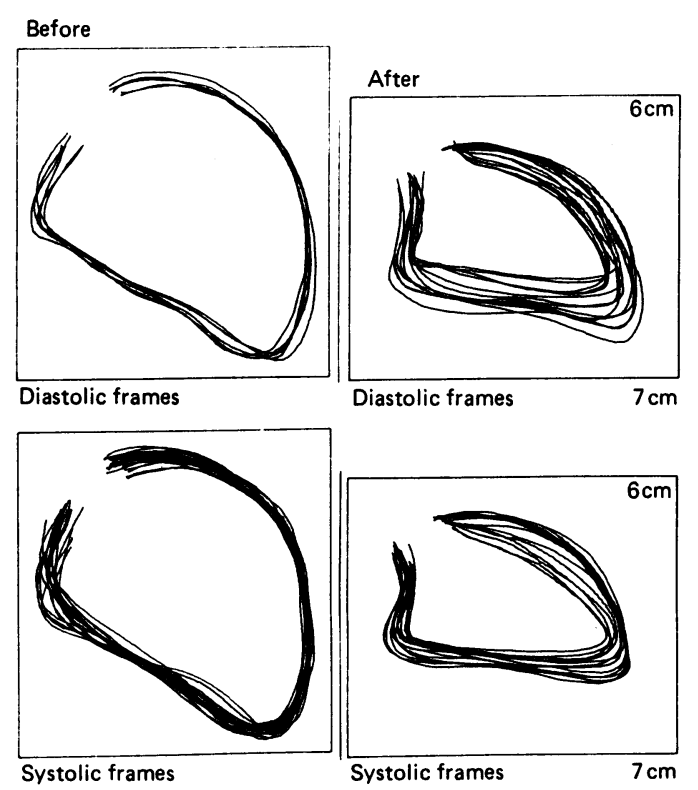

Figure 1 Cavity outlines obtained from patient 4 in systole and diastole before and after reimplantation. There was global improvement in the amplitude of wall motion. 
Values derived from frame by frame analysis of left ventricular angiograms

\begin{tabular}{|c|c|c|c|c|c|c|c|}
\hline \multirow[b]{2}{*}{ Patient } & \multirow{2}{*}{$\begin{array}{l}\text { Age at } \\
\text { operation } \\
\text { (mnth) }\end{array}$} & \multicolumn{2}{|c|}{$E F(\%)$} & \multicolumn{2}{|c|}{$E D S I(\%)$} & \multicolumn{2}{|c|}{ Shape index change (\%) } \\
\hline & & Before & After & Before & After & Before & After \\
\hline $\begin{array}{l}1 \\
2 \\
3 \\
4 \\
5 \\
\text { Median }\end{array}$ & $\begin{array}{l}4 \cdot 7 \\
4 \cdot 0 \\
5 \cdot 7 \\
2 \cdot 8 \\
3 \cdot 8\end{array}$ & $\begin{array}{l}18 \\
22 \\
23 \\
\frac{21}{21} \cdot 5^{\star}\end{array}$ & $\begin{array}{l}\overline{74} \\
40 \\
70 \\
69 \\
69 \cdot 5^{\star}\end{array}$ & $\begin{array}{l}87 \cdot 5 \\
85 \\
92 \\
89 \\
\overline{88} \cdot 2^{\star}\end{array}$ & $\begin{array}{l}\overline{81} \\
77 \\
81 \\
77 \cdot 5 \\
79^{\star}\end{array}$ & $\begin{array}{l}0 \\
5 \\
0 \\
7 \\
\frac{-5}{2 \cdot 5 \dagger}\end{array}$ & $\begin{array}{l}\overline{13 \cdot \bar{j}} \\
5 \\
13 \\
16 \\
13 \cdot 5 \dagger\end{array}$ \\
\hline
\end{tabular}

Mann-Whitney U test: ${ }^{\star} p<0 \cdot 03$; $\uparrow$ NS. EDSI, end diastolic shape index; EF, ejection fraction.

oblique view were digitised frame by frame to study abnormalities of wall movement before and after operation. ${ }^{7}$ Plots of superimposed cavity outlines were obtained in systole and diastole (fig 1). The cavity area was calculated by numerical integration, and volumes, derived from the area (area-length method $^{8}$ ) were used to calculate ejection fraction. The left ventricular shape index, a measurement of the "roundness" of the cavity outline, was derived from single plane angiograms as $4 \pi$ (cavity area) $/$ (perimeter) $)^{2}$. The maximum shape index is 1 , or $100 \%$, when the cavity outline is circular, and cavity obliteration gives a value of zero. The shape index of the normal left ventricle decreases by approximately $20 \%$ during systole. ${ }^{9}$ Thus a substantial part of ejection can be accounted for by the change in cavity shape alone, rather than global myocardial shortening.

Plots of local wall movement were displayed against time. The left ventricular cavity outline was divided into 40 equal segments at end diastole. The wall position in each frame was then measured in $\mathrm{mm}$ along a line defined for each of these segments to the nearest point on the end systolic outline. Wall movement was displayed to give a three dimensional impres-

Figure 2 Plots of shape index obtained from patient 4. Before operation the cavity was more circular at end diastole (time = $0 \mathrm{~s}$ ), and there was little change in cavity shape during the cardiac cycle. After

reimplantation the degree of systolic shape change had increased suggesting improvement in global systolic function.
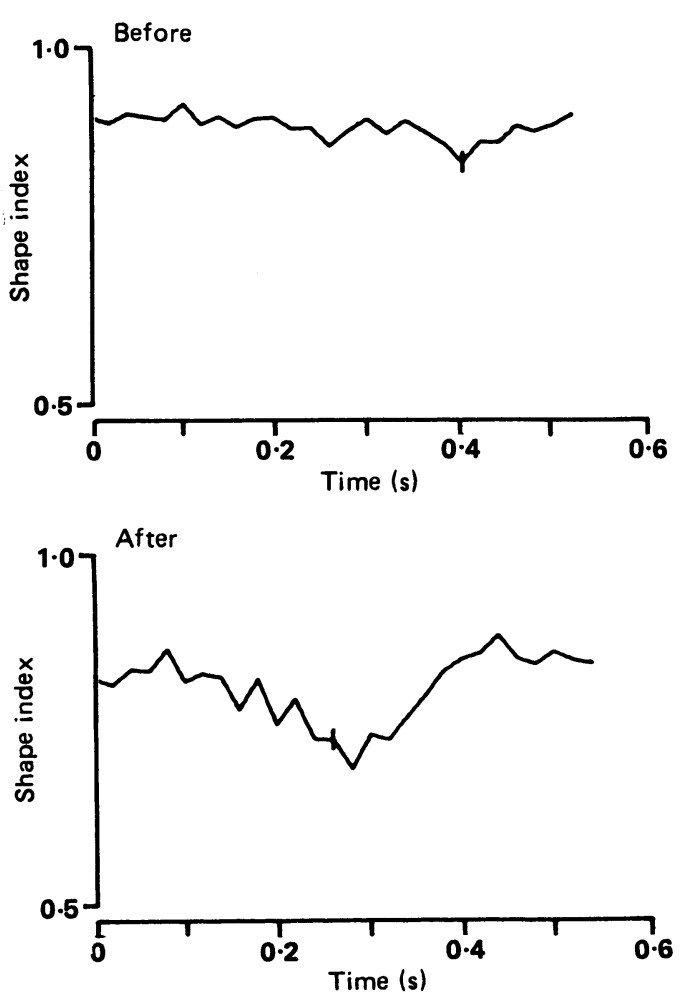

sion (isometric wall motion plot), where inward movement was an upward deflection, or as a series of contour lines joining points which had the same displacement (contour wall motion plot). Successive contours represent inward or outward movements of $1 \mathrm{~mm}$. The two vertical lines show times of minimum cavity area and mitral valve opening. ${ }^{7}$ Onset of inward motion is marked " $\mathrm{X}$ " for each segment. ${ }^{10}$

\section{Results}

PATENCY OF ANASTOMOSIS

The four patients who were re-evaluated had direct reimplantation of the anomalous coronary artery into the aorta. All anastomoses were patent at a minimum follow up time of 22 months. The remaining patient who underwent repair via an intrapulmonary baffle showed clinical improvement one year later and the state of the anastomosis will be assessed at the end of a longer follow up. This infant had a baffle type of repair because the origin of the left coronary artery was a sheath of small vessels arising from the pulmonary artery.

\section{GLOBAL LEFT VENTRICULAR FUNCTION}

The table shows the indices of global left ventricular function. The ejection fraction was severely impaired (median 21.5\%) before operation but returned to normal in all but one patient (median $69.5 \%$ ) after operation. The left ventricular cavity (fig 2 ) was more circular than normal at end diastole (greater end diastolic shape index) and showed a lesser degree of change in shape during systole (lower systolic index change). The end diastolic shape index decreased after operation $(p<0.03)$ and there was a tendency for the degree of systolic shape change to increase; both features are compatible with improved global systolic function (fig 2).

\section{LOCAL WALL MOVEMENT}

The very low amplitude of wall movement seen preoperatively made it difficult to analyse regional wall motion in isometric and contour wall motion plots. Similar plots after operation showed a considerable improvement of the pattern of wall motion (figs 3-5). Plots were considered to be within normal limits in three of the four patients who were recatheterised. Shape changes were normal with synchronous onset of inward motion (marked with $\mathrm{X}$ for each segment) in all of these patients and there was no evidence of pathological asynchrony during isovolumic relaxation (figs 3 and 4). In the remaining child there were residual abnormalities. Figure 5 shows the isometric and contour plots from this patient. The onset of inward motion was delayed in the anterior region. Furthermore, outward motion of segments in the inferior region began before mitral valve opening - that is, during isovolumic relaxation. This child was the oldest one in this series at the time of operation ( $5 \cdot 7$ months). 

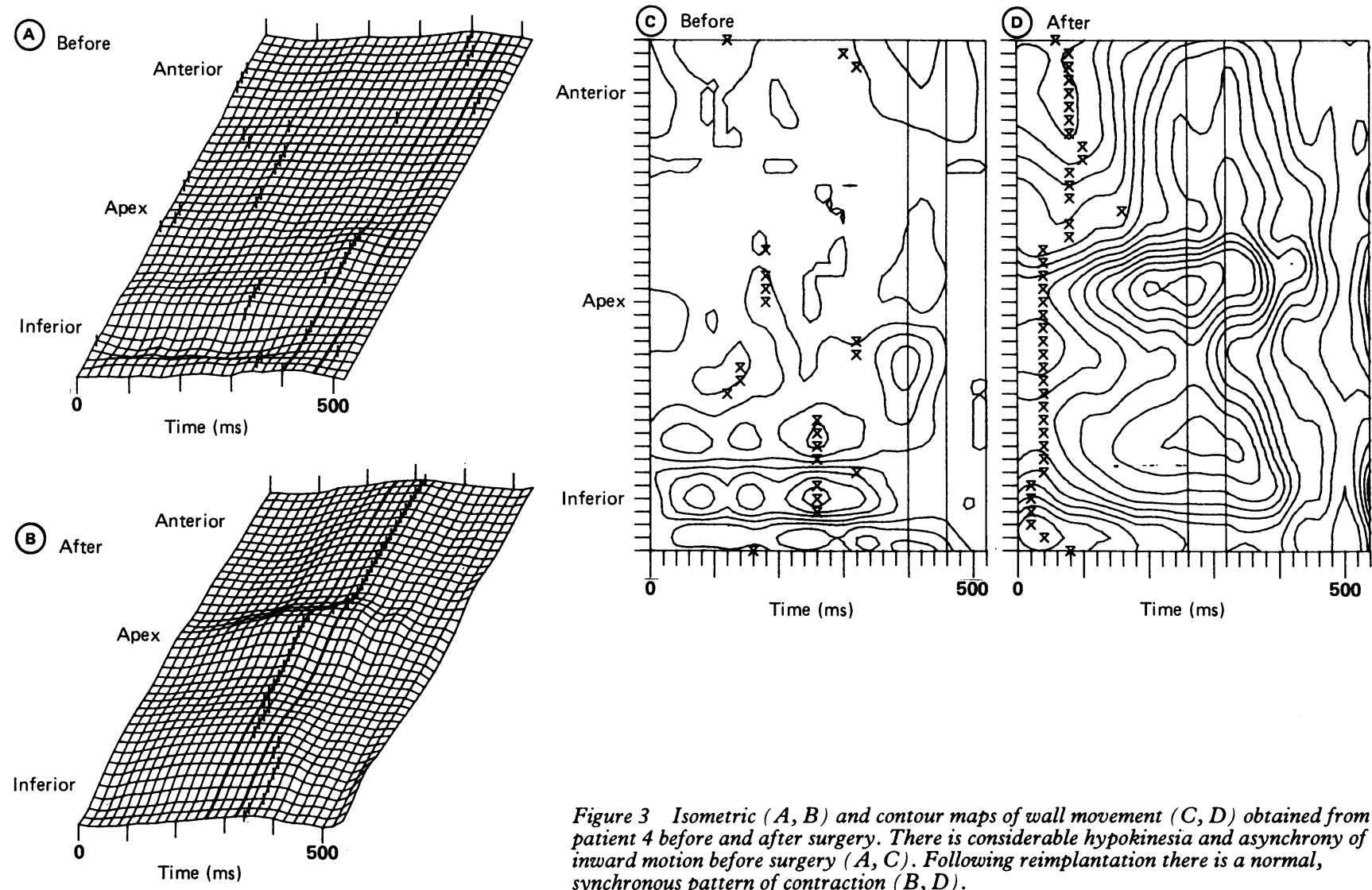

Figure 3 Isometric $(A, B)$ and contour maps of wall movement $(C, D)$ obtained from patient 4 before and after surgery. There is considerable hypokinesia and asynchrony of inward motion before surgery $(A, C)$. Following reimplantation there is a normal, synchronous pattern of contraction $(B, D)$.
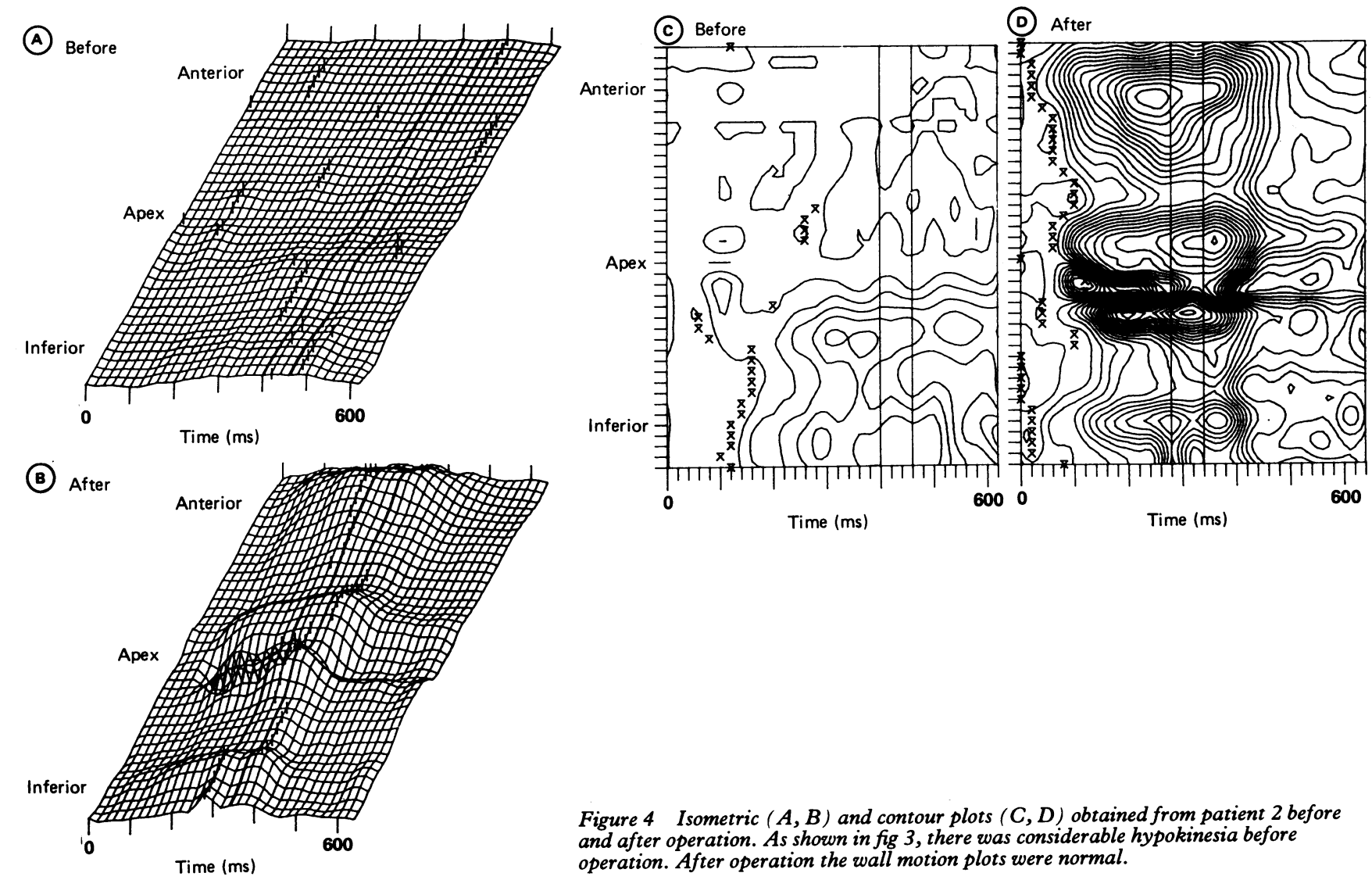
and after operation. As shown in fig 3, there was considerable hypokinesia before operation. After operation the wall motion plots were normal. 


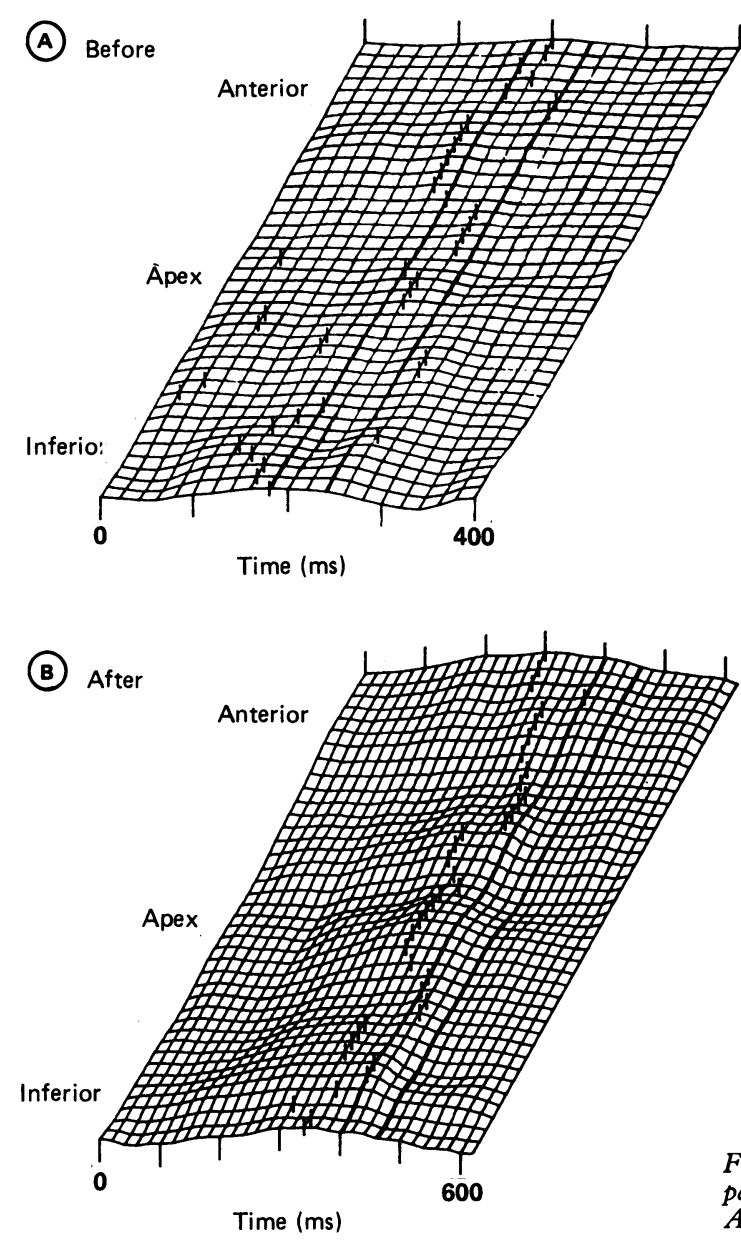

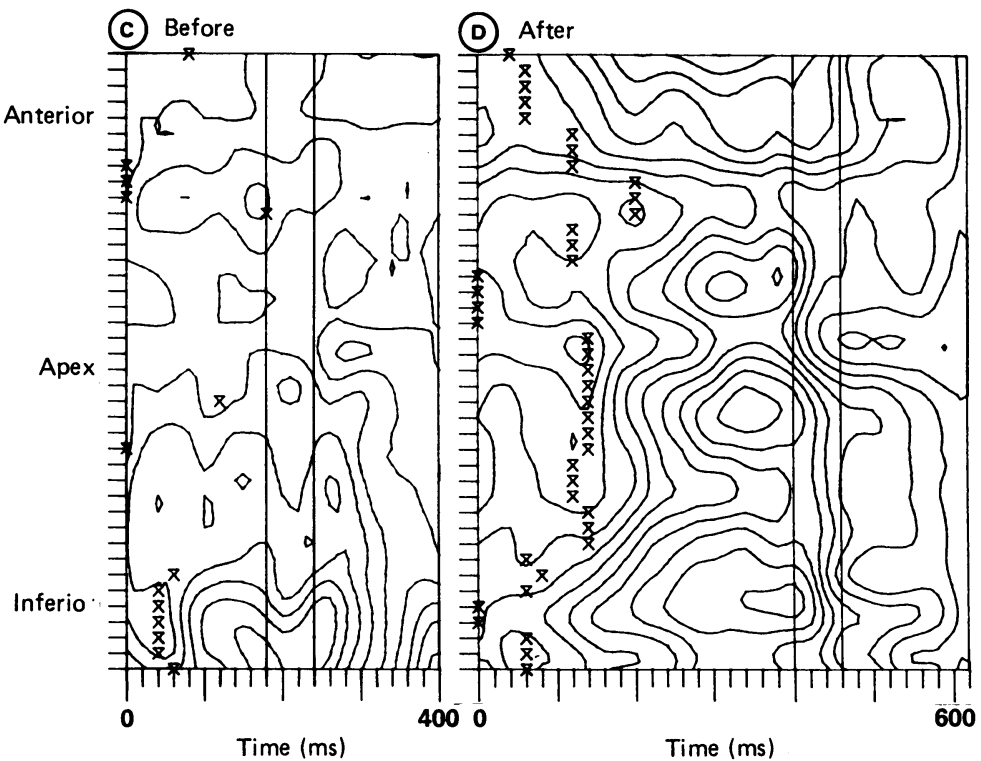

Figure 5 Isometric $(A, B)$ and contour wall motion $(C, D)$ plots obtained from patient 3 before and after operation. There was generalised hypokinesia before operation. After reimplantation the amplitude of wall motion improved. See text for details.

\section{Discussion}

Reported surgical mortality for an anomalous coronary artery in infancy in the early 1980s was as high as $75-80 \%{ }^{1112}$ and a delay of operation was therefore advocated. ${ }^{11}$

With new techniques of obtaining a dual coronary artery system either by direct reimplantation or redirection of the coronary artery, the chances of early survival have improved. ${ }^{1314}$ In our series there was no operative mortality, as in other recent series. $^{51516}$ The high patency rate of the anastomosis in the patients who underwent direct reimplantation also supports the use of this technique even for very sick and young infants. Early surgical intervention with establishment of a dual coronary artery system now seems to be the best option for infants with symptoms. ${ }^{15} 1718$

In 1980, Levitsky et al reported one case of improvement of ejection fraction, assessed by echocardiography, after reimplantation of the anomalous coronary artery into the aorta. ${ }^{19}$ There was also evidence of improved contraction, ${ }^{16}$ ejection fraction, ${ }^{15} 18$ and shortening fraction $^{17}$ after restoration of a dual coronary artery system early in life. Rein and colleagues in $1987^{5}$ reported improvement in regional and global function assessed by echocardiography before and after the use of Takeuchi's technique $^{3}$ in five infants. Preoperatively they did not find localised abnormalities of ventricular function but rather a uniform reduction of the shortening fraction for various segments studied with no segment-to-segment variation.
Analysis of global left ventricular function in four of our patients after operation showed a similar considerable improvement of global systolic function in all patients. Not only did the ejection fraction increase but the normal change in left ventricular shape reappeared. Local wall movement became normal in timing and extent in three patients, and in one child residual localised hypokinesia and asynchrony persisted during isovolumic relaxation. Despite this, the ejection fraction increased strikingly and the child is now symptom free. This child was the oldest at the time of operation and while no firm conclusions can be drawn about the optimal timing of operation, it seems reasonable to suggest that the earlier the operation is performed the greater the chance of myocardial recovery and return to a normal systolic function.

There can be no doubt that early reimplantation or redirection of an anomalous coronary artery is the best treatment for infants with symptoms. It is attended by a low mortality, has a high rate of anastomotic patency, and dramatically improves left ventricular function. Whereas our data on left ventricular function confirm the previously published data, the demonstration of full recovery of regional ventricular function in our patients is unique. Synchronous contraction returns, reflecting normal interrelations between the various functional units of the ventricular myocardium. Presumably therefore, they were not lost even though the cavity was dilated and the amplitude of endocardial motion was greatly 
reduced. There is further support for recommending direct reimplantation wherever possible.

Longer term follow up is obviously required, but short and medium term results are already encouraging and indicate longer survival and a better quality of life for these children.

1 Driscoll DJ, Nihill MR, Mullins CE, Cooley DA, McNamara DG. Management of symptomatic infants
with anomalous origin of the left coronary artery from the with anomalous origin of the left coronary artery

2 Neches WH, Mathews RA, Park SC, et al. Anomalous origin of the left coronary artery from the pulmonary artery. A new method for surgical repair. Circulation 1974;50: 582-7.

3 Takeuchi S, Imamura H, Katsumoto K, et al. New surgical method for repair of anomalous left coronary artery from pulmonary artery. J Thorac Cardiovasc Surg 1979;78: pulmo

4 Hamilton DI, Ghosh PK, Donnelly RJ. An operation for anomalous origin of left coronary artery. $\mathrm{Br}$ Heart $\mathrm{J}$ 1979;41:121-4.

5 Rein AJJT, Colan SD, Parness IA, Sanders SP. Regional and global left ventricular function in infants with and global left ventricular function in infants with anomalous origin of the left coronary artery from the pulmonary trunk: preoperative and

6 McComb JM, Vincent R, Hilton CJ. Recurrent ventricular tachycardia associated with anomalous left coronary artery from the pulmonary artery in a child managed by revascularisation and map-guided endocardial resection. Br Heart J 1989;62:396-9.

7 Gibson DG, Prewitt TA, Brown DJ. Analysis of left ventricular wall movement during isovolumic relaxation and its relation to coronary artery disease. $\mathrm{Br}$ Heart $J$ 1976;38:1010-9.
8 Sandler M, Dodge HT. The use of single plane angiograms for the calculation of left ventricular volume in man. $\mathbf{A m}$ Heart $J 1968 ; 75: 325-40$

9 Gibson DG, Brown DJ. Continuous assessment of left ventricular shape in man. Br Heart $J$ 1975;37:904-10.

10 Gibson DG, Greenbaum RA, Pridie RB, Yacoub MH. Correction of left ventricular asynchrony by coronary artery surgery. Br Heart $J$ 1988;59:304-8.

11 Driscoll DJ, Nihill MR, Mullins CE, Cooley DA, McNamara DG. Management of symptomatic infants with anomalous origin of the left coronary artery from the pulmonary artery. Am J Cardiol 1981;47:642-8.

12 Laborde $F$, Marchand $M$, Leca F, Jarreau MM, Dequirot $A$ Hazan E. Surgical treatment of anomalous origin of the left coronary artery in infancy and childhood. Early and late results in 20 consecutive cases. $J$ Thorac Cardiovasc Surg 1981;82:423-8.

13 Grace RR, Angelini P, Cooley DA. Aortic implantation of anomalous left coronary artery arising from pulmonary anomalous left coronary artery arising

14 Arciniegas E, Farooki Z, Hakimi M, Green E. Management of anomalous left coronary artery (ALCA) from the pulmonary artery (PA). Circulation 1980;62(suppl 1): $180-9$

15 Bunton R, Jonas RA, Lang P, Rein AJJT, Castaneda AR. Anomalous origin of the left coronary artery from pulmonary artery. Ligation versus establishment of a two coronary artery system. J Thorac Cardiovasc Surg 1987, 93:103-8.

16 Menahem S, Venables AW. Anomalous left coronary artery from the pulmonary artery: a 15 year sample. Br Heart 1987;58:378-84.

17 Vouché PR, Baillot-Vernant F, Trinquet F, et al. Anomalous left coronary artery from the pulmonary artery in infants. Which operation? When? J Thorac Cardiovasc in infants. Which operat

18 Guikahue MK, Sidi D, Kachaner J, et al. Anomalous left coronary artery arising from the pulmonary artery in infancy: Is early operation better? $\mathrm{Br}$ Heart 1988;60:522-6

19 Levitsky S, Van der Horst RL, Hastreiter AR, Fisher EA Anomalous left coronary artery in the infant. Recovery of left ventricular function following early direct aortic reimplantation. J Thorac Cardiovasc Surg 1980;79: 598-602. 